\title{
The Evaluation Index System Research on Quality Engineering Based on AHP \\ Jiangtao You $^{1}$ and Wei Liu ${ }^{2}$ \\ ${ }^{1,2}$ Henan College of Transportation \\ a1951539785@qq.com,
}

\author{
Keywords: Quality Engineering; Evaluating Indicator; AHP; Highway water transportation \\ engineering
}

\begin{abstract}
For the sake of accelerate the modern engineering management, promote the transformation and upgrading of highway and waterway engineering construction and development, improve the quality, safety and operation service level of highway and waterway engineering. This article puts forward the construction of the quality engineering of highway water transportation which include planning and design, construction management, construction quality, ecological landscape, traffic culture and service capacity. This article combines Delphy Method and analytic hierarchy process (AHP) to analyze the weight of the index, select the engineering to carry on the empirical evaluation. Finally, this paper examines the scientificity and rationality of the evaluation index system.
\end{abstract}

\section{Introduction}

The concept of "Quality Engineering"has promoted the internal quality and external grade of modern engineering management. Internal quality refers to the function, durability, reliability, safety, applicability and so on. The external grade refers to the beauty of architectural art, the beauty of engineering technology, strong transportation culture and service ability.

\section{Construction the Index System}

Scientific, perfect and reasonable establishment of the evaluation index system for the quality of highway transportation quality is the precondition for comprehensive evaluation of highway water transport engineering, application of analytic hierarchy process and fuzzy comprehensive evaluation.

\section{The principle of the index system establishing}

The Principle of Combination of Guidance and Maneuverability. The selection of the indicators should not only take into account the possibility of the implementation of each engineering, but also have a certain orientation and forward-looking. Meanwhile, In terms of technology, management mechanism, brand building and other aspects, we should encourage engineering to innovate according to local conditions, forming bright spots and constantly improving the overall level of highway engineering management.

The Principle of Combination of Process Evaluation and Engineering Effect. Each index in the evaluation system should not only pay attention to the actual effect of the evaluation of the engineering, but also pay attention to every link in the engineering construction. The index should have the attribute of evaluate of the built and building engineering. It has practical significance to guide the engineering on the construction process.

The Principle of Combination of Qualitative and Quantitative Analysis. The evaluation index system of highway quality engineering is very complex, some indexes can be quantified and some cannot. The intrinsic quality of the engineering could evaluate by the current and quantifiable standard of inspection and evaluation. For indicators that cannot be quantified, could qualitative analysis can be used to illustrate the meaning of the index.

The Principle of Non-correlation. The content of highway quality engineering involves the various stages of design, construction, operation and maintenance. It includes quality, safety, scientific and technological innovation, green, low carbon and culture. In the process of selecting 
the evaluation index, we should try to avoid the intersecting repeatability among the indexes, which is beneficial to the construction of the evaluation index system.

\section{Construction of Quality Engineering Index System}

\section{The route of evaluation index system}

First of all, it is necessary to determine the premise of the evaluation of the highway water transportation engineering, to determine the purpose of evaluation, to formulate the evaluation principles and to make clear the scope of the evaluation.

Secondly, carried out the primary selection of the index, determined the main contents of the evaluation index system, analysis the qualitative or quantitative and interpretation of each index.

Lastly, we should comprehensively evaluate the index system, determine the evaluation method, calculate the index weight, select engineering for trial evaluation, determine whether the evaluation result is effective, and finally determine the evaluation index system.

\section{The content of the evaluation index system}

After analysis the factors that affect the quality of highway and waterway engineering, solicit expert opinion, establish the evaluation index system, the evaluation and screening according to expert advice, selects 6 first level indicators, 22 second level indicators and 67 third level indicators.

\section{Determination of Weight}

AHP is a systematic and hierarchical analysis method combining quantitative and qualitative. AHP was proposed by American operational research scientist A.L.Safety in 1970s. It is a method which cans analysis the multi index system scheme in a hierarchical and structured way. It makes the decision makers model and quantify the decision thinking process of complex systems. Application of using the AHP, The decision maker can decompose the complex problem into several factors and several levels, comparison and calculation among various factors, the weight of different schemes can be obtained, it provides the basis for the choice of the best decision.

In general, it can be divided into six steps:

\section{Step 1: Establishing hierarchical structure}

Building a hierarchical analysis structure model, AHP can be used to solve the related problems in the field of economic management. This level is divided into three layers: the target layer, the standard layer and the index layer.

The target layer: It includes the target and the result of the target. There is only one element in this layer.

The standard layer: It is an intermediate link to achieve the goal. It can be divided into several levels. For example, the standard layer I, the standard layer II and so on.

The index layer: The options and targets for achieving goals and guidelines

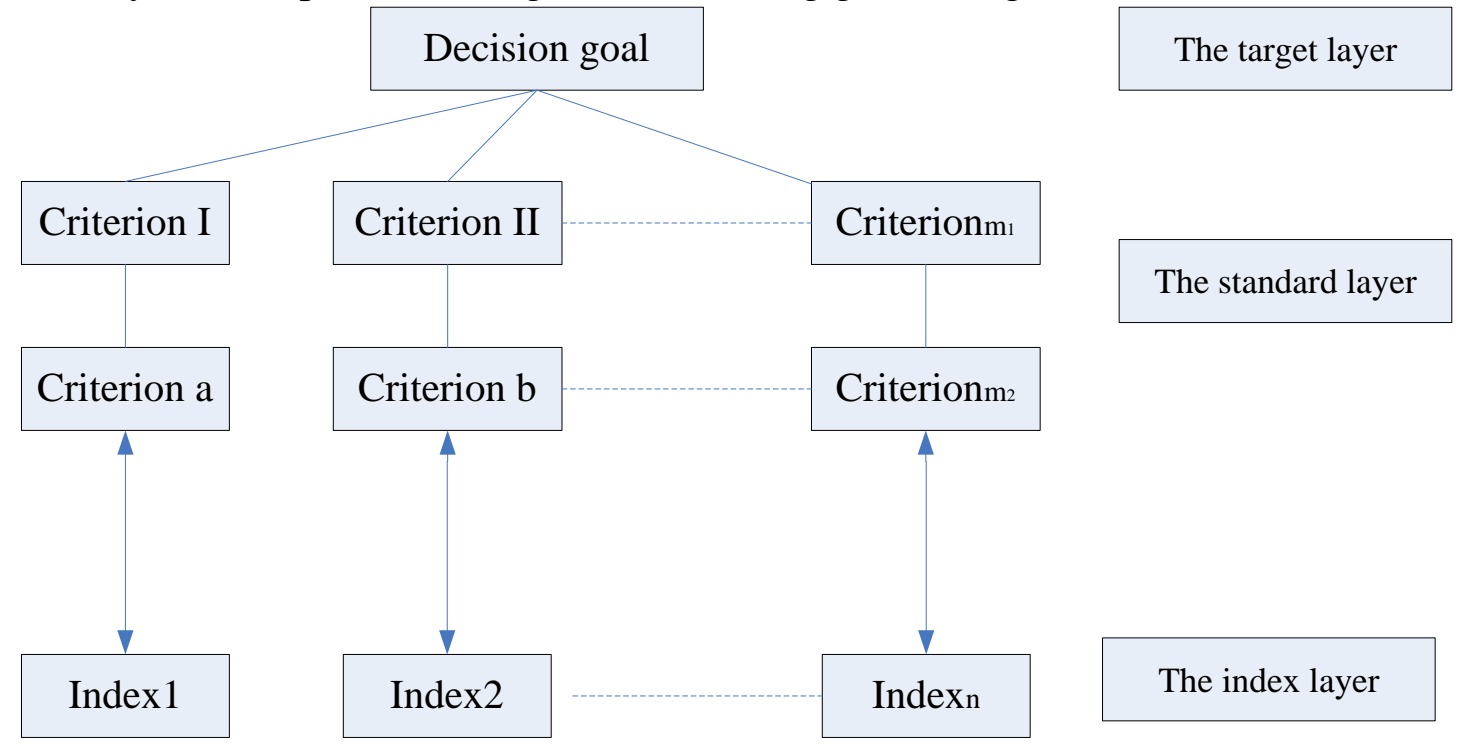

Figure 1. Hierarchical structure diagram 
The number of layers in hierarchical is related to the complexity and exhaustion of the analytical problems. If you want to analyze the problem in detail, you need to build a good hierarchy.

\section{Step 2: Constructing the judgment matrix of comparison}

AHP uses a comparison method to derive the mutual weight of criteria and indicators. It can make a corresponding judgement based on the experts think the importance of various factors at each level. Then all these judgments are represented by the appropriate scale and the numeric value, and then they are written as the judgment matrix.

For the n elements, The judgment matrix of the comparison is $C=\left(C_{i j}\right)_{n \times n}$, The judgment matrix of the structure is as follows:

$$
\begin{array}{c|cccc}
B_{k} & C_{1} & C_{2} & \ldots & C_{n} \\
\hline C_{1} & C_{11} & C_{12} & \ldots & C_{1 n} \\
C_{2} & C_{21} & C_{22} & \ldots & C_{2 n} \\
\ldots & \ldots & \ldots & \ldots & \ldots \\
C_{n} & C_{n 1} & C_{n 2} & \ldots & C_{n n}
\end{array}
$$

When solving the actual problems encountered, the judgment matrix often shows the characteristics that are not necessarily consistent. Therefore, in this case, the consistency check must be carried out.

\section{Step 3: Checking the consistency of judgment matrix}

The consistency test is to test the coordination between the elements' importance and avoid the conflicting phenomena between the elements. In the AHP method, lead into the negative mean value of the other characteristic roots outside the maximum eigenvalue of the matrix, use this as an indicator of the deviation of the judgment matrix from the consistency.

$$
C I=\frac{\lambda_{\max }-n}{n-1}
$$

To test the consistency of decision makers' judgement thinking, the smaller the CI value, it shows that the better the consistency of the judgment matrix is better. The greater the CI value, the greater the degree of deviation from the complete consistency of the judgment matrix.

\section{Step 4: Hierarchical single order}

The relative importance of a factor at a certain level relative to a certain factor in the previous level, it can be reduced to the maximum characteristic root and the eigenvector problem of the calculation judgment matrix.

Calculation of the product of each element in a judgement matrix $M_{i}$.

$$
M_{i}=\prod_{j=1}^{n} a_{i j} \quad \mathrm{i}=1,2, \ldots, \mathrm{n}
$$

Calculation of the n square root $\bar{W}_{i}$ of $M_{i}$

$$
\bar{W}_{i}=\sqrt[n]{M_{i}}
$$

Normalization of vector $\bar{W}=\left[\overline{W_{1}}, \overline{W_{2}}, \ldots, \overline{W_{n}}\right]^{T}$

$$
W_{i}=\frac{\overline{W_{i}}}{\sum_{j=1}^{n} \overline{W_{j}}}
$$

Then $W=\left[W_{1}, W_{2}, \ldots, W_{n}\right]^{T}$ is the eigenvector.

The maximum eigenvalue of the calculation judgment matrix: $\lambda_{\max }$ 


$$
\lambda_{\max }=\sum_{i=1}^{n} \frac{(A W)_{i}}{n W_{i}}
$$

Step 5: Total ranking of layers.

According to the hierarchical structure, a layer by layer calculation should be carried out from the upper layer of the upper layer. Thus, the ranking values of the lowest level relative to the relative importance of the highest level can be calculated.

Step 6: Make the corresponding decision based on the results of the previous steps

Finally through consistency test, it is concluded that the weight of quality engineering evaluation index is as follows:

Table 1 Weight of Quality Engineering Evaluation Index

\begin{tabular}{|c|c|c|c|}
\hline $\begin{array}{l}\text { The Target } \\
\text { Layer (I) }\end{array}$ & $\begin{array}{l}\text { Evaluation } \\
\text { (A) }\end{array}$ & $\begin{array}{l}\text { Assessment } \\
\text { Element (B) }\end{array}$ & Main Observation Point (C) \\
\hline \multirow{25}{*}{$\begin{array}{l}\text { Evaluation } \\
\text { Index of } \\
\text { Highway } \\
\text { Quality } \\
\text { Engineering }\end{array}$} & \multirow{17}{*}{$\begin{array}{l}\text { Planning } \\
\text { and Design } \\
\mathrm{A}_{1} \\
(0.4113)\end{array}$} & \multirow{3}{*}{$\begin{array}{l}\text { Planning } \\
\text { Thought } \\
\mathrm{B}_{11}(0.3587)\end{array}$} & Planning conformance $\mathrm{C}_{111}(0.2923)$ \\
\hline & & & Planning Necessity $\mathrm{C}_{112}(0.6270)$ \\
\hline & & & Planning Rationality $\mathrm{C}_{113}(0.0807)$ \\
\hline & & \multirow[t]{4}{*}{$\begin{array}{l}\text { Design Idea } \\
\mathrm{B}_{12}(0.3190)\end{array}$} & $\begin{array}{l}\text { The Concept of Security Supremacy } C_{121} \\
(0.5178)\end{array}$ \\
\hline & & & $\begin{array}{l}\text { The Concept of Green Environmental } \\
\text { Protection } \mathrm{C}_{122}(0.0796)\end{array}$ \\
\hline & & & Life Cycle Cost Concept $\mathrm{C}_{123}(0.2289)$ \\
\hline & & & $\begin{array}{l}\text { The Idea of "People-Oriented" } \mathrm{C}_{124} \\
(0.1738)\end{array}$ \\
\hline & & \multirow{4}{*}{$\begin{array}{l}\text { Art of Design } \\
B_{13}(0.0543)\end{array}$} & LinearC $_{131}(0.4748)$ \\
\hline & & & StructureC $_{132}(0.1374)$ \\
\hline & & & Roadside Facilities $\mathrm{C}_{133}(0.2281)$ \\
\hline & & & Landscape along the Line $\mathrm{C}_{134}(0.1598)$ \\
\hline & & \multirow{4}{*}{$\begin{array}{l}\text { Design } \\
\text { Technique } \\
\mathrm{B}_{14}(0.2072)\end{array}$} & $\begin{array}{l}\text { Application of New Technology and New } \\
\text { Idea } C_{141}(0.0902)\end{array}$ \\
\hline & & & Bridge Risk Assessment $\mathrm{C}_{142}(0.2637)$ \\
\hline & & & Risk Management $\mathrm{C}_{143}(0.5745)$ \\
\hline & & & Achievement Award $\mathrm{C}_{144}(0.0715)$ \\
\hline & & \multirow{2}{*}{$\begin{array}{l}\text { Design } \\
\text { Services } \\
B_{15}(0.0608)\end{array}$} & Technical DisclosureC $_{151}(0.2500)$ \\
\hline & & & Field ServiceC $C_{152}(0.7500)$ \\
\hline & \multirow{8}{*}{$\begin{array}{l}\text { Construction } \\
\text { Management } \\
\mathrm{A}_{2(0.2065)}\end{array}$} & \multirow{2}{*}{$\begin{array}{l}\text { Basic } \\
\text { construction } \\
\text { procedure } \\
\mathrm{B}_{21}(0.1593)\end{array}$} & Project Approval Document $\mathrm{C}_{211}(0.3333)$ \\
\hline & & & $\begin{array}{l}\text { Traffic or Completion Acceptance } \mathrm{C}_{212} \\
(0.6667)\end{array}$ \\
\hline & & \multirow{6}{*}{$\begin{array}{l}\text { Construction } \\
\text { Management } \\
\mathrm{B}_{22}(0.5889)\end{array}$} & $\begin{array}{l}\text { Project Management Specialization } \mathrm{C}_{221} \\
(0.2040)\end{array}$ \\
\hline & & & Management Information $\mathrm{C}_{222}(0.0650)$ \\
\hline & & & $\begin{array}{l}\text { Standardization of Construction } \text { WorkC }_{223} \\
(0.1436)\end{array}$ \\
\hline & & & Quality Assurance $\mathrm{C}_{224}(0.2888)$ \\
\hline & & & Project Cost Control $\mathrm{C}_{225}(0.1178)$ \\
\hline & & & Construction Time Control $\mathrm{C}_{226}(0.0988)$ \\
\hline
\end{tabular}




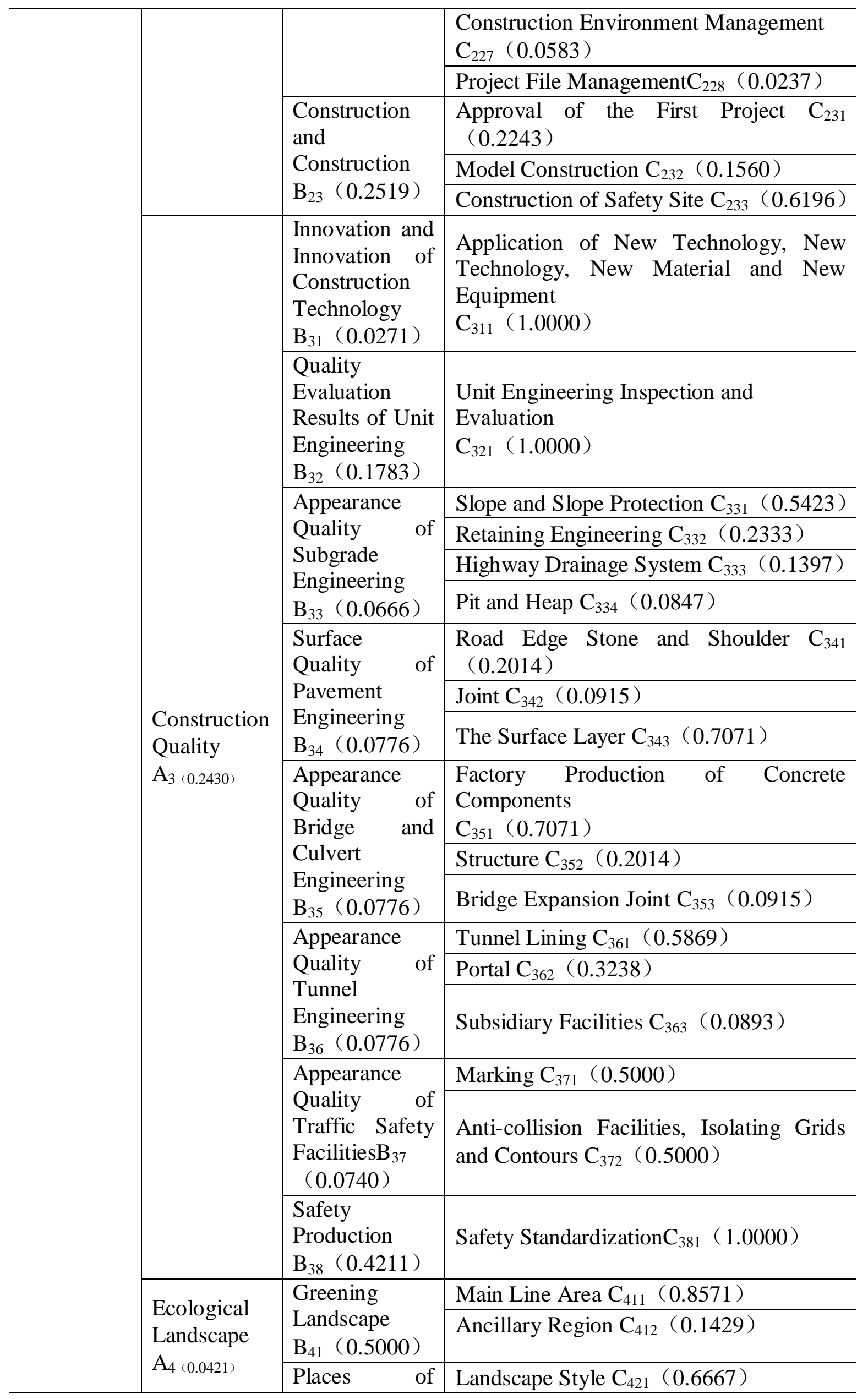




\begin{tabular}{|c|c|c|}
\hline & $\begin{array}{l}\text { Historic } \\
\text { Figures and } \\
\text { Cultural } \\
\text { heritage } \\
\mathrm{B}_{42}(0.5000)\end{array}$ & $\begin{array}{l}\text { Main Structure and Functional Area } \mathrm{C}_{422} \\
(0.3333)\end{array}$ \\
\hline \multirow{5}{*}{$\begin{array}{l}\text { Traffic } \\
\text { Culture } \\
\text { A } 5(0.0358)\end{array}$} & \multirow[t]{3}{*}{$\begin{array}{l}\text { Spiritual } \\
\text { Culture } \\
\mathrm{B}_{51}(0.6500)\end{array}$} & $\begin{array}{l}\text { The Construction of the Party } \\
\text { Organization at the Grass-roots Level } \mathrm{C}_{511} \\
(0.2014)\end{array}$ \\
\hline & & $\begin{array}{l}\text { The Construction of Spiritual Civilization } \\
\mathrm{C}_{512}(0.1179)\end{array}$ \\
\hline & & Team Building $\mathrm{C}_{513}(0.6806)$ \\
\hline & \multirow{2}{*}{$\begin{array}{l}\text { Environmental } \\
\text { CultureB }_{52} \\
(0.3500)\end{array}$} & Green DevelopmentC $\mathrm{C}_{521}(0.8333)$ \\
\hline & & Road Culture $\mathrm{C}_{522}(0.1667)$ \\
\hline \multirow{10}{*}{$\begin{array}{l}\text { Service } \\
\text { Capacity } \\
\mathrm{A}_{6}(0.0613)\end{array}$} & \multirow{2}{*}{$\begin{array}{l}\text { Service } \\
\text { Facilities } \\
\mathrm{B}_{61}(0.3333)\end{array}$} & $\begin{array}{l}\text { Service Area and Parking } \text { AreaC }_{611} \\
(0.8000)\end{array}$ \\
\hline & & Toll Gate $\mathrm{C}_{612}(0.2000)$ \\
\hline & \multirow{8}{*}{$\begin{array}{l}\text { Operation } \\
\text { Management } \\
\mathrm{B}_{62}(0.6667)\end{array}$} & Budget ManagementC $_{621}(0.1031)$ \\
\hline & & Service EnvironmentC $_{622}(0.0640)$ \\
\hline & & Electromechanical System $\mathrm{C}_{623}(0.0945)$ \\
\hline & & Maintenance Management $\mathrm{C}_{624}(0.1581)$ \\
\hline & & Traffic Information Release $\mathrm{C}_{625}(0.0636)$ \\
\hline & & Ensure Visibility of Space $\mathrm{C}_{626}(0.1082)$ \\
\hline & & Emergency Security $\mathrm{C}_{627}(0.3769)$ \\
\hline & & Management Database $\mathrm{C}_{628}(0.0317)$ \\
\hline
\end{tabular}

\section{Conclusion}

According to the above established quality engineering evaluation index system and the calculated weight of each index, select an empirical analysis of a project as a trial evaluation object. Through the process and results of empirical analysis that the quality engineering evaluation index system constructed in this paper has certain applicability and operability. But the index system still has some inadaptability, it is necessary to increase the scope of application and improve it.

\section{References}

[1] Todd Litman. Sustainable transportation and TDM [R].Victoria Transport Policy Institute, 2009.

[2] Transportation's Role in Reducing U.S. Greenhouse Gas Emission Volume: Synthesis Report [R] U.S. Department of Transportation, 2010.

[3] Beynon. MJ. A Method of Aggregation in DS/AHP for Group Decision-Making with the Non-Equivalent Importance of Individuals in the Group [J]. Computers and Operations Research 2005, 32(7):1881-1896

[4] Wu Yan, Du Dong. AHP Evaluation Software Design and Empirical Research. [J]. Computer Systems \& Applications 2008.11.

[5] GUO Ying-shi, YUAN Wei,FU Rui Research on Characteristics of Assessment Indexes for Road Safety Journal of Highway and Transportation Research and Development 2006.05 